\title{
Thickness study of vanadium carbide interface for deposition of DLC films
}

\section{Estudo da espessura da interface do carboneto de vanádio para deposição de filmes de DLC}

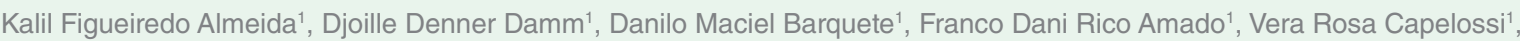

Nila Cecília de Farias Lopes Medeiros ${ }^{1}$, Leonardo lusuti Medeiros ${ }^{1}$

\begin{abstract}
PECVD (Plasma Enhanced Chemical Vapor Deposition) technique allows growth of wear-resistant and antifriction hard DLC films, with prevalence of $\mathrm{sp}^{3}$ bonds in relation to hydrogen bonds. This paper presents an experimental evaluation of vanadium carbide layer (VC) thickness formed by reactive thermodiffusion process (TRD) for subsequent deposition of DLC. The salt bath is prepared by mixing the reagents: sodium tetraborate decahydrate, vanadium pentoxide and boron carbide. A crucible with lid was used, with capacity of 25 grams. The PECVD parameters used: 200 Torr vacuum, argon at $1.5 \mathrm{sccm},-600 \mathrm{~V}$ at 0.05 Torr for 20 minutes; acetylene at $1 \mathrm{sccm},-750 \mathrm{~V}$ for 40 minutes at 0.07 Torr and $180^{\circ} \mathrm{C}$. AISI H13, $\mathrm{D} 2$ and $\mathrm{O} 1$ tool steels were used as substrates. The layers of VC were characterized by SEM, EDX and XRD, and the DLC films were characterized by SEM, EDX, indentation tests and Raman spectroscopy. The oxygen showed to be harmful to the growth of $\mathrm{VC}$ layers on steel substrates by reactive thermodiffusion process. The utilization of conical internal geometry with lid crucible were effective and contributed to the stabilization of thermodiffusion process, restricting oxygen environment and ensuring complete immersion of the sample, and allowing the growth of uniform and homogeneous VC layers suitable for subsequent deposition of DLC films.
\end{abstract}

Keywords: PECVD; Diamond-Like Carbon;Vanadium Carbide.

\section{RESUMO}

O processo PECVD (Plasma Enhanced Chemical Vapor Deposition), permite o crescimento de filmes de DLC duros, resistentes ao desgaste e antifriccionantes, com uma prevalência de ligações $\mathrm{sp}^{3}$ em relação às ligações de hidrogênio. Este artigo apresenta uma avaliação experimental da espessura da camada de carboneto de vanádio (VC), formado por termodifusão reativa (TRD) para deposição de DLC. O banho de sal é preparado pela mistura dos reagentes: tetraborato de sódio decahidratado, pentóxido de vanádio e carboneto de boro. Foi utilizado um cadinho com tampa com capacidade de 25 gramas. Os parâmetros utilizados do processo PECVD foram: vácuo a 200 Torr, inserção de argônio a 1,5 sccm, $-600 \mathrm{~V}$ e pressão de 0,05 Torr durante 20 minutos; inserção de acetileno a $1 \mathrm{sccm}$, $-750 \mathrm{~V}$ durante 40 minutos, pressão de 0,07 Torr a $180{ }^{\circ} \mathrm{C}$. Foram utilizados como substratos os aços-ferramenta AISI H13, D2 e O1. As camadas de VC foram caracterizadas por SEM, EDX e XRD, e os filmes de DLC foram caracterizados por SEM, EDX, ensaios de indentação e espectroscopia Raman. O oxigênio mostrou-se prejudicial para o crescimento de VC em substratos de aço pelo processo TRD. A utilização do cadinho com geometria interna cônica com tampa foi eficaz e contribuiu para a estabilização do processo de termodifusão, restringindo atmosfera de oxigênio e permitindo o crescimento de camadas uniformes e homogêneas de VC, adequadas para a deposição de DLC.

Palavras-chave: PECVD; Carbono Tipo Diamante; Carboneto de Vanádio.

\footnotetext{
${ }^{1}$ Universidade Estadual de Santa Cruz - Departamento de Ciências Exatas e Tecnológicas - Programa de Ciência, Inovação e Modelagem em Materiais Ilhéus (BA) - Brazil

Correspondence author: Kalil Figueiredo Almeida - Departamento de Ciências Exatas e Tecnológicas - Programa de Ciência, Inovação e Modelagem em Materiais - Rod. Jorge Amado (Salobrinho), Km 16 - CEP 45662-900 - Ilhéus (BA) - Brazil

E-mail: kalilfig@gmail.com
}

Received: 08/31/2015 Approved: 03/09/2015 


\section{INTRODUCTION}

The metastable synthetic diamond has been widely studied in the production of thin films for cutting tools, tool steels and self-lubricating applications ${ }^{(1)}$, enabling new synth reactors with high-density plasma. Hybrid materials with $\mathrm{sp}^{2}$ and $\mathrm{sp}^{3}$ bonds, named diamond like carbon (DLC), present properties similar to diamond $^{(2)}$.

Hydrogenated amorphous carbon film (a-C:H) with polymer characteristics (hydrocarbon) can be obtained by the deposition method. This is the most popular method among laboratories deposition methods ${ }^{(3)}$. This technology uses chemical reaction processes that typically require high temperatures, but high density plasma allows a deposition of thin films at lower substrate temperatures, favoring the growth of DLC films on complex geometries with high hardness even at the nanometer scale ${ }^{(4)}$.

The PECVD process uses a dielectric potential for plasma generation. Gas molecules $\left(\mathrm{C}_{2} \mathrm{H}_{2}\right.$ - acetylene $)$ in the process are dissociated, allowing the formation of radicals that are immediately deposited on the substrate. The electric discharge is driven by two electrodes, connected to a radio frequency source (RF). The discharge provides the energy required for ionization of molecules, which form the plasma by the ionic dissociation of the acetylene molecules, which are broken to produce an ion bombardment on the substrate to deposit DLC thin film. The film growth process of diamond/DLC requires the control of the deposition rate and nucleation. Acetylene gas is the most suitable for the DLC film due to higher deposition rate of film, lower percentage of $\mathrm{H}_{2}$, lower operating voltage $(\mathrm{eV})$ for molecules ionization and better film adhesion ${ }^{(3)}$.

Vanadium carbide (VC) is one of the hardest among the transition metals carbides (molybdenum, titanium and silicon carbides) with distinct properties for cutting tools applications ${ }^{(5,6)}$. They have been used in studies for deposition of thin diamond and DLC films due to its good toughness and high wear resistance in the processes of plastic forming and machining metals ${ }^{(7)}$. VC high toughness also contributes to reduce residual surface stresses in DLC films. The vanadium carbide has an intermediate thermal expansion coefficient $\left(6,08 \times 10^{-6} \mathrm{~K}^{-1}\right)$ between steel and diamond $\left(1,1 \times 10^{-6} \mathrm{~K}^{-1}\right)$, indicating this transition metal carbide as the most suitable to be used as interlayer between steel substrates and the DLC films ${ }^{(8)}$.

Another aspect of the vanadium carbide formed by reactive thermodiffusion process is its extremely hardness, reaching
2460-3150 HV (Hard Vickers), and its non-porous and extremely fine grain structure, around 0.3-5 $\mu \mathrm{m}^{(8)}$.

This paper presents an experimental evaluation of the thermodiffused vanadium carbide layer on steel substrates AISI H13, D2 and O1 (Table 1), in order to control the oxidation reactions in the process and providing an effective interface for subsequent deposition of DLC.

\section{EXPERIMENTAL}

The method consists in promoting the formation of $\mathrm{VC}$ thermodiffused layer in a salt bath containing reagents: sodium tetraborate decahydrate $\left(\mathrm{Na}_{2} \mathrm{~B}_{4} \mathrm{O}_{7} \cdot 10 \mathrm{H}_{2} \mathrm{O}\right)$, vanadium pentoxide $\left(\mathrm{V}_{2} \mathrm{O}_{5}\right)$ and boron carbide $\left(\mathrm{B}_{4} \mathrm{C}\right)$ at proportion of 75,20 and $5 \%{ }^{(8)}$, respectively. Steel substrates immersed in the salt bath are heated at temperatures ranging from $850{ }^{\circ} \mathrm{C}$ to $1050^{\circ} \mathrm{C}{ }^{(5,6)}$. The reactive thermodiffusion process is effective carbon content higher than $0.3 \%$ in the austenite, at TRD process temperature, and it is influenced by alloy elements in the steel substrate ${ }^{(5)}$.

The thermodiffusion reactive process takes place in five distinct steps: obtaining steel tablets (samples) for machining, polishing and cleaning of samples, preparation of reagents, thermodiffusion and cleaning thermodiffused sample. The first step consists in machining steel bars with circular cross section to obtain tablets between $10-15 \mathrm{~mm}$ in diameter and $3 \mathrm{~mm}$ thickness. The second step consists of performing the polishing of the steel samples with Sander and Polisher Model PLF FORTEL with mesh 220, 600 and 1200 sand paper. The steel samples are cleaned in an ultrasonic bath of $30 \mathrm{ml}$ acetone solution 58.08\% using a Cleaner Model LS-1.8 D-3/X Sonic Limp in for 5 minutes. A nitric acid solution at $8 \%$ is used to remove surface oxides and other impurities. The washing process with ultrasonic bath of acetone is repeated for another 5 minutes. The third step consists in preparing the reagents, weighed on precision balance Model TE214S to obtain 25 grams of a mixture with $18.75 \mathrm{~g}(75 \%)$ of $\mathrm{Na}_{2} \mathrm{~B}_{4} \mathrm{O}_{7} \cdot 10 \mathrm{H}_{2} \mathrm{O}$, $5 \mathrm{~g}(20 \%)$ of $\mathrm{V}_{2} \mathrm{O}_{5}$ and $1.25 \mathrm{~g}(5 \%)$ of $\mathrm{B}_{4} \mathrm{C}$.

The fourth step consists in the growth of $\mathrm{VC}$ layer by reactive thermal diffusion process, where the sample is immersed into the mixture contained in the crucible already heated to $150{ }^{\circ} \mathrm{C}$. The crucible is placed back in the oven and kept at $150{ }^{\circ} \mathrm{C}$ for 5 minutes to stabilize temperature. Temperature is then gradually increased to $650{ }^{\circ} \mathrm{C}$, to complete dehydration of the salt and to control volumetric expansion of the mixture. This is critical

Table 1: Composition of steel substrates ${ }^{(9)}$.

\begin{tabular}{c|c|c|c|c|c|c|c|c|c|}
\hline \multirow{2}{*}{ Group AISI } & \multicolumn{7}{|c}{ Chemical Composition } \\
\cline { 2 - 10 } & C & Mn & P & S & Si & Cr & Mo & Total \\
\hline AISI H13 & 0,40 & 0,35 & 1,00 & - & 1,00 & 5,15 & 1,40 & 9,30 \\
\hline AISI O1 & 0,90 & 1,20 & 0,30 & 0,50 & 0,50 & 0,50 & - & 3,90 \\
\hline AISI D2 & 1,50 & 0,40 & 1,10 & - & 0,40 & 12,00 & 0,95 & 16,35 \\
\hline
\end{tabular}


stage, since the salt mixture tends to expand and might expose the sample to the internal atmosphere of the crucible, until the salt is completely dehydrated. Finally, temperature is gradually increased to $950{ }^{\circ} \mathrm{C}$, the effective process temperature, for 3.5 hours. The temperature is reduced to $750^{\circ} \mathrm{C}$, which is the lowest temperature at which the moisture has enough viscosity to permit removal of the sample from the crucible. The last step consists of boiling the sample to remove the excess residues on the sample surface.

One of the steps to stabilize the TRD process was the development of a crucible with conical internal geometry (Fig. 1), with enough volumetric capacity to avoid exposition to atmosphere and oxidation of the sample. The crucible geometry and internal volume allowed the sample to be kept completely immersed during the thermal expansion stage and TRD process. AISI 304 stainless steel was the selected material for crucible manufacturing due to its stability in the process conditions temperature and chemical etching. Laboratory crucibles are usually cylindrical, with volumetric capacity of 15 grams. This configuration has shown to be inefficient, requiring its removal from the oven during the thermal expansion process to restrain the expanding salt the mixture inside the crucible and exposing the sample and the crucible to atmospheric environment in the temperature range of $350^{\circ} \mathrm{C}$ to $650^{\circ} \mathrm{C}$ and consequently exposing sample and crucible to oxygen attack.

The DLC deposition process was controlled by voltage, which determines the deposition rate, and by pressure, used to generate the plasma in the PECVD process. The PECVD reactor (Fig. 2) has a cylindrical stainless steel chamber with a volume of $25 \mathrm{~L}$. Firstly, vacuum 200 Torr is made in the PECVD reactor chamber; argon is then inserted as inert gas to remove contaminants inside the chamber, at 0.05 Torr, $1.5 \mathrm{sccm}$ and $-600 \mathrm{~V}$ for 20 minutes. Next, acetylene gas $\left(\mathrm{C}_{2} \mathrm{H}_{2}\right)$ is inserted in the chamber as a source of hydrocarbon for DLC deposition, the temperature is increased to $180^{\circ} \mathrm{C}$ at 0.07 Torr, $1 \mathrm{sccm}$ and $-750 \mathrm{~V}$, for 40 minutes. At the end of DLC growth the temperature is gradually reduced, to avoid sudden reduction in temperature and film delamination due to

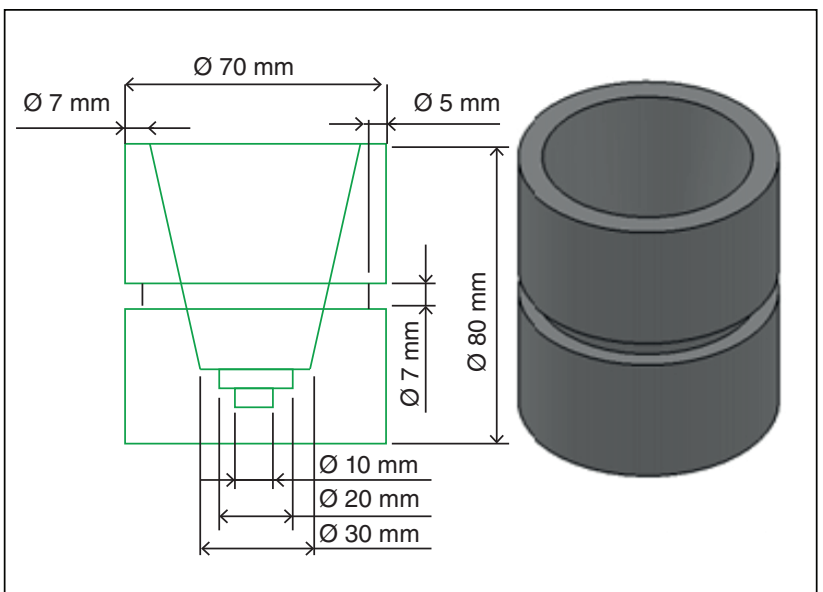

Figure 1: Project crucible conical stainless steel 304 series. thermal expansion coefficient difference between the steel and the DLC.

The layers of VC were characterized by scanning electron microscopy (SEM-EDX) and X-ray diffraction. The deposited DLC films were characterized by scanning electron microscopy (SEM-EDS), indentation tests and Raman spectroscopy.

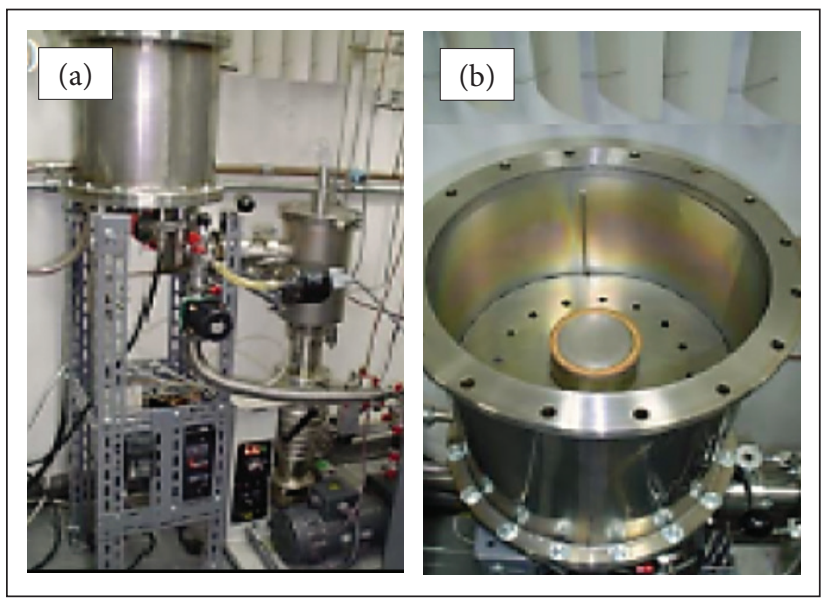

Figure 2: PECVD Reactor - External (a) and Internal (b).

\section{RESULTS AND DISCUSSION}

The initial stage of this work was related to the stabilization of the thermodiffusion process in the aggressive atmospheric environment (excess $\mathrm{O}_{2}$ ). AISI D2 samples were used in this phase. SEM images (EDS) and the EDX spectra of central region of sample surface showed high peaks of oxygen and iron due to boron consumed by reacting with atmospheric oxygen (Fig. 3a, b), for experiments performed with the cylindrical crucible. Without boron protection $\left(\mathrm{V}_{2} \mathrm{O}_{5}\right.$ reducer element), oxygen in excess migrates and promotes iron oxide formation on substrate surface. The diffusion for $\mathrm{VC}$ formation is compromised by ceasing the reduction of $\mathrm{V}_{2} \mathrm{O}_{5}$, inhibiting the reaction of free vanadium with the carbon from substrate. Vanadium atoms in excess form a highly rough and brittle surface of crystalline vanadium, indicating necessity of improvements in the experimental arrangement, particularly in the cylindrical crucible geometry.

The excess of oxygen from atmosphere was controlled by changing the crucible internal shape to conical internal geometry and including a lid. EDX spectrum and MEV image of the sample surface central region shows reduction of oxygen and iron peaks (Fig. 4 a, b) and with the formation of VC. This prevents the boron depletion in the reaction, suitably protecting the diffusional process for $\mathrm{VC}$ formation. This new crucible configuration showed effective in forming the VC layer, both due to 1.67 times higher volume that control molten salt overflow and its internal angle that ensures sample completely immersion during TRD process. The control of oxygen in excess promoted a more homogeneous VC layer growth with $2.7 \mu \mathrm{m}$ thickness as shown in Fig. $5 \mathrm{a}$ of the sample cross section. 
After process stabilization with AISI D2 steel substrate, the new standard method has been applied to AISI H13 and AISI O1 substrates. VC coatings $2.2 \mu \mathrm{m}$ (Fig. $5 \mathrm{~b}$ ) and $5.3 \mu \mathrm{m}$ (Fig. $5 \mathrm{c}$ ) thick, for AISI H13 and AISI O1 substrates, respectively, were obtained as shown in the cross section of the samples. The TRD process for VC coatings in different types of steel alloys showed influence of alloying elements in the coating characteristics, affecting their morphology and thickness. For AISI D2 substrates, even with $1.5 \%$ carbon, the layer thickness were lower than for AISI O1 ( $0.90 \%$ carbon), factor probably associated to 16.35 $\%$ of the total amount of alloying elements in AISI D2 steel ${ }^{(9)}$, justifying the lower VC layer thickness. This might be due to lower carbon atoms diffusibility in steel matrix with higher alloy elements content - AISI O1 steel has only 3.90\% of total content of alloying elements. The VC growth in steel AISI H13 is limited by the low percentage of carbon $(0.40 \% \mathrm{C})$, justifying the smallest thickness presented in the work. X-rays diffraction analysis in the steel sample identified the chemical composition of the VC crystalline phases in each type of steel, with $\mathrm{V}_{8} \mathrm{C}_{7}$ in the AISI D2, $\mathrm{V}_{6} \mathrm{C}_{5}$ in the AISI $\mathrm{H} 13$ and AISI O1, the latter has shown to be the more effective for higher VC layer thickness formed (Fig. 5d).

The deposition of DLC on steel substrates using the VC interlayer followed the same parameters for all types of steel.
The hardness of the DLC depends on the ratio between $\mathrm{sp}^{2}$ and $\mathrm{sp}^{3}$ bonds, morphology, and presence/absence of alloying elements on the substrate, and the characteristic peaks of the type DLC film aC:H, identified by Raman spectroscopy, located approximately between $1350 \mathrm{~cm}^{-1}$ and $1560 \mathrm{~cm}^{-1(3)}$. The Raman spectra showed characteristic peaks of DLC (Fig.5d) with $1369.03 \mathrm{~cm}^{-1}$ in band D and $1526.97 \mathrm{~cm}^{-1}$ in band G. SEM images (Fig. 6a, b) demonstrated that the DLC film growth in AISI D2 and AISI H13 showed low adhesion and propagation of circumferential cracks in indentation tests, due to their low percentage of carbon in $\mathrm{H} 13(0.4 \% \mathrm{C})$ - factor which limits the growth of $\mathrm{VC}(2.2 \mu \mathrm{m})$, and high percentage of alloying elements in D2 (Table 1) - other factor which limits the VC layer growth $(2.7 \mu \mathrm{m})$, that led to defects in DLC by the high state of compressive surface stresses. For AISI O1steel, the SEM image (Fig. 6c) indicates effectiveness in the DLC deposition, resulting very homogeneous film and highly adherent to substrate, according to the results of indentation tests and absence of circumferential cracks. Higher VC interlayers $(5.3 \mu \mathrm{m})$ tends to provide surface relaxation and to provide higher resistance to delamination. In this case, effects are classified as acceptable and corresponding to high adhesion of DLC film, according to 3198 VDI standard for indentation tests ${ }^{(10)}$.

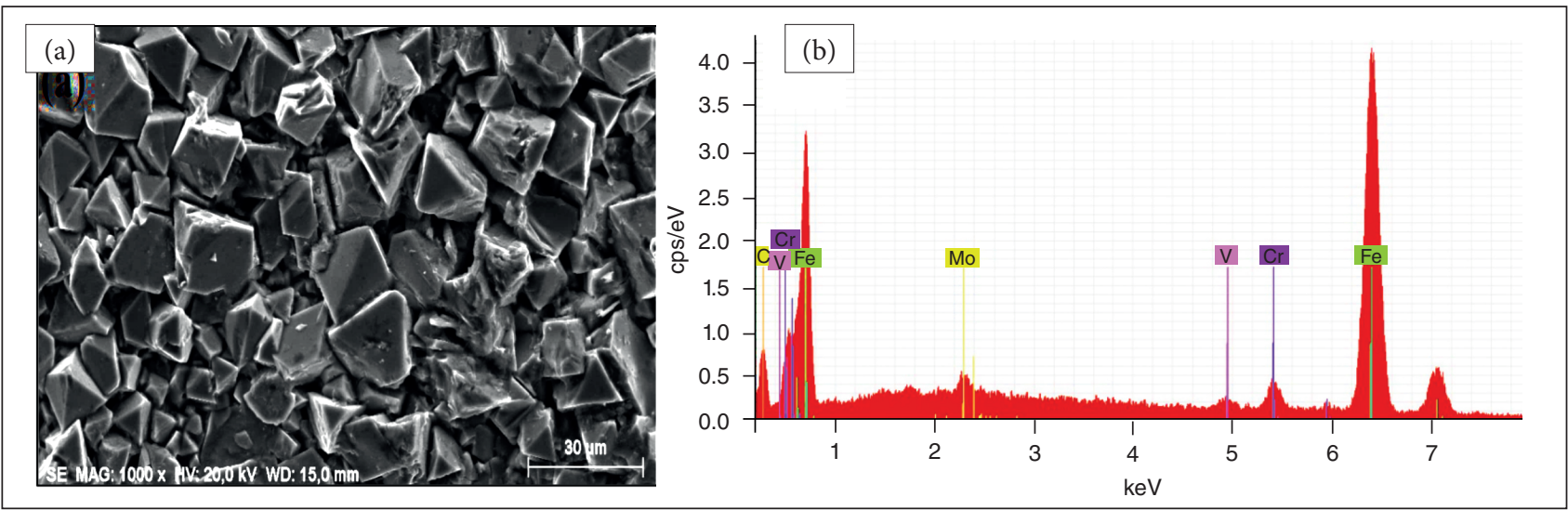

Figure 3: VC-TD on AISI D2 (a) surface image and (b) EDX of surface.

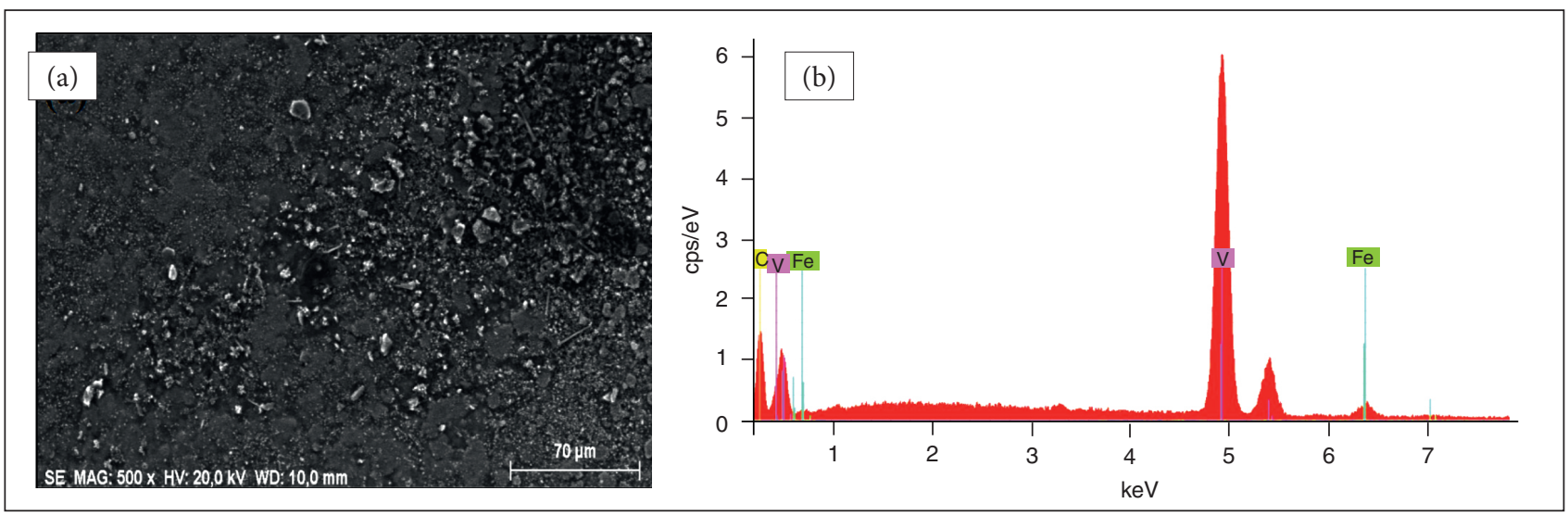

Figure 4:VC-TD on AISI D2 (a) surface image and (b) EDX of surface. 

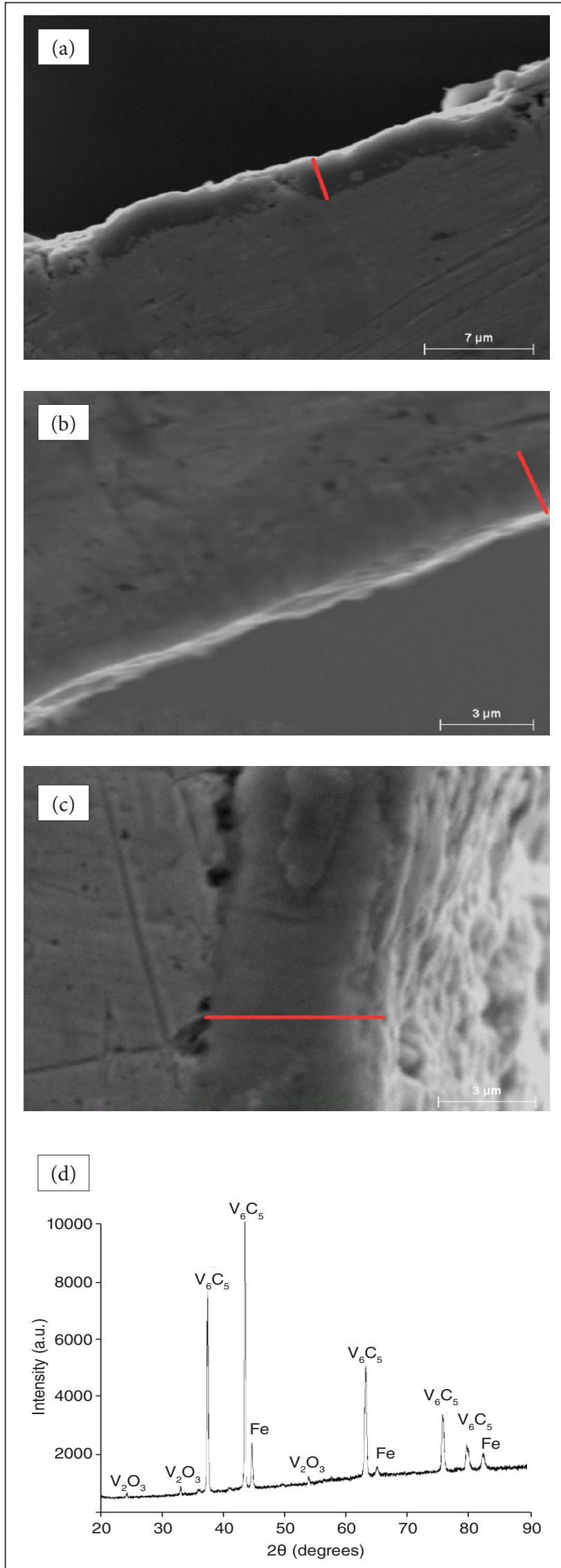

Figure 5: Thicknesses AISI D2 (a), AISI H13 (b), AISI O1 (c) and DRX analysis of AISI O1 (d).
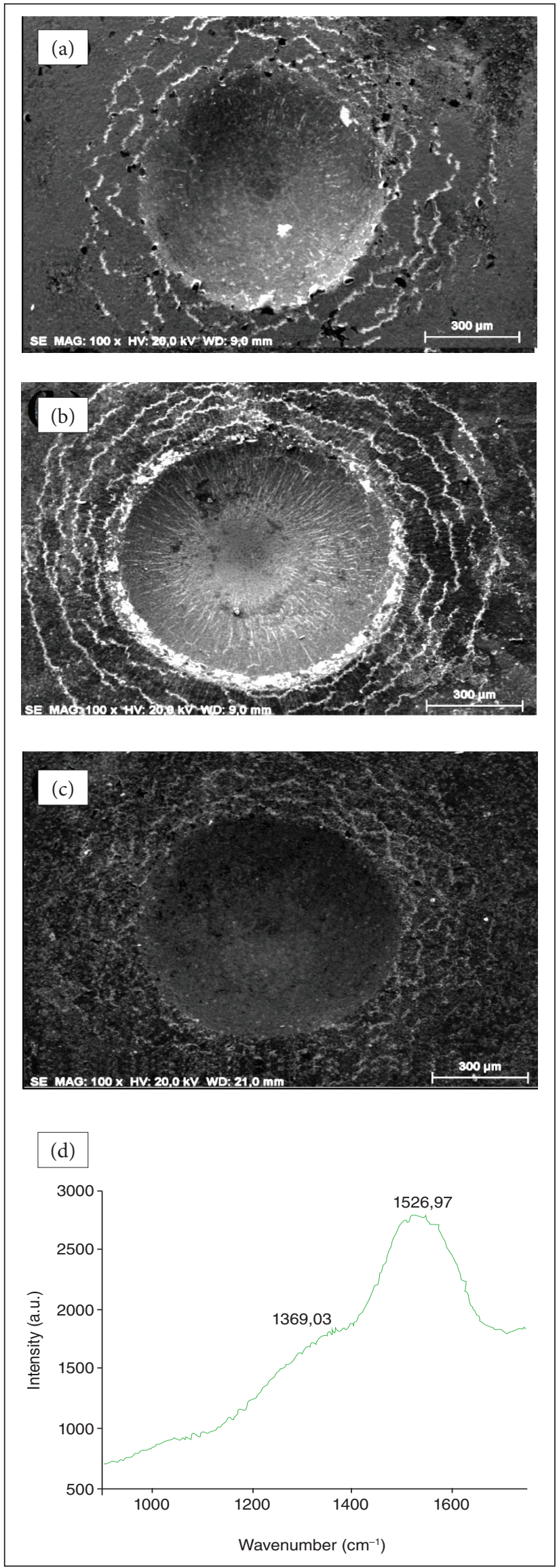

Figure 6: Indentation AISI D2 (a) AISI H13 (b) and AISI O1 (c) and Raman analysis of AISI 01 (d). 


\section{CONCLUSIONS}

The oxygen from atmosphere proved to be harmful to growth in thermodiffused VC coatings on steel substrates because it inhibits the reaction between the $\mathrm{VC}$ forming elements and provides oxidation on the substrate surface. The development of a crucible with internal conical geometry and with a lid contributed to the stabilization of thermodiffusion process, restricting efficiently oxygen in excess and ensuring complete immersion of the sample in molten salt during the thermodiffusion process. The carbon content in the steel substrate associated with the alloying elements is fundamental to the growth of $\mathrm{VC}$, since the greater the percentage of carbon the more favorable to the formation of thicker VC coatings. The sample with AISI O1 steel substrate enabled the formation of VC layer with the largest thickness among the other substrates. The highest adhesion of the DLC films obtained were obtained for thicker layers thermodiffused VC layers, as observed from indentation tests.

\section{REFERENCES}

1. CHIANG, Y; BIRNIE III, D; KINGERY, W.D., Physical Ceramics: Principles for Ceramic Science and Engineering, 1997.
2. HOLMBERG, K; MATTHEWS, A., Coatings Tribology: Properties, Techniques and Applications in Surface Engineering. Amsterdam: Editora Elsevier Science B.V., 1994

3. ROBERTSON, J., Diamond-like amorphous carbon. Materials Science and Engineering, pp. 129-281, 2002.

4. CAMPOS, J.T. G. A. E. A.; CONTIN, A.; Trava-Airoldi, V. J.; MARQUES V. E. C.; ALMEIDA, E.C.; CORAT, E.J.; BARQUETE, D. M., Residual stress analysis by different bias voltage of DLC films on AISI 4050 alloy steel. Revista Brasileira de Aplicações do Vácuo on Line, v. 34 p. 123-127, 2015

5. CHICCO, B.; BORBIDGE, W.E.; SUMMERVILLE E., Experimental study of vanadium carbide and carbonitride coatings. Mater Sci Eng A 1999; 266(1-2): 62-72.

6. ARAI, T.; HARPER, S.; ASM Handbook, vol. 4, Heat Treating, ASM International, USA, 1991, p. 448.

7. WOYDT, M.; SKOPP, A.; DORFEL, I.; WITKE, K., Wear engineering oxides/anti-wear oxides. Wear 1998; 218(1):84-95.

8. BARQUETE, D. M.; CORAT, E. J. ; CAMPOS, R. A.; MOURA NETO C.; TRAVA-AIROLDI, V. J. Thermodiffused vanadium carbide interface for diamond films on steel and cemented carbides substrates. Surface Engineering, v. 26, p. 506-510, 2010.

9. FAVORIT ACCOS ESPECIAIS, Available from: < http://www.favorit.com $\mathrm{br} /$ sites/default/files/tabelas/acos_ferramentas_0.html. Access from: 09/25/2015

10. VEREIN DEUTSCHER INGENIEURE NORMEN, VDI 3198, VDIVerlag, Dusseldorf, 1991. 